\title{
The issue of a responsible agent in technological civilization
}

\author{
Anastasia Platonova $^{1 \mathrm{a}}$, Maria Kokarevich ${ }^{1}$, Tatiana Shapovalova ${ }^{1}$ \\ ${ }^{1}$ Tomsk State University of Architecture and Building, Solyanaya sq., 2, 634003 Tomsk, Russia
}

\begin{abstract}
In our days, responsibility has become the most problematic aspect of almost all human actions, including influencing nature, scientific prognostication, and simulation of the future. The problem of responsibility is a sign of the crisis which we experience now, resulting from the gap between activities and knowledge about their consequences. Human activity has a mediated and collective nature, which makes it difficult to name the subject of responsibility. Therefore, it is necessary to examine the subjective aspect of responsibility related to the technological activity and conditions in which such liability may be plausibly attributed to any subject. Scientific and technological rationality is not a sufficient approach to face new problems ahead of us. Technological progress and moral crisis make us realize that we need a new moral system. Particularly, the idea of moral responsibility can be represented as a filter for technological innovations. However, the notion of moral responsibility has some restrictions when we attempt to apply it for technological activities. Analyzing the functions of multiform subjects of responsibility is a prerequisite to our understanding of the way in which scientific and technological progress shapes the contemporary society. We are trying to focus on the complicated notion of Collective Responsibility, which is, on the one hand, needs some philosophical implications due to appearance of new social changes and, on the other hand, analyzes the idea which allows reconstructing the whole discussion context. First of all, the authors attempt to show the main issues, which appear when researchers use this idea in their investigations. Simultaneously, the article describes the state of moral responsibility in Philosophy on the whole, where the authors define the Individual notion of responsibility, which is deeply rooted in the Western philosophical way of thinking.
\end{abstract}

\section{Introduction}

Considerations about moral responsibilities which have been focused on ethical discussions today deal with are rather complicated circumstances in modern society. First of all, the main issue is responsible agents of moral responsibility for the scientific and technological progress has existential significance today. Fuel, energy and ecological crises are all the result of a technogenic mentality. Our aggressive interference with the natural world has shown clearly that nature is not going to last forever, since its stock of resources is limited. If mankind wastes the resources and variety of organic life, the world around it will become featureless, dumb and aimless. First of all, this issue has enough courses to make us think. Technological enterprises and their side effects affect and meddle in the lives of many people who are not in direct contact with them. Today technological activity has a mediated and collective character, so it is difficult to find a subject of responsibility. As a result, it is nearly impossible for persons to be aware of their degree of responsibility, because we cannot imagine all the consequences of our activities in the modern world. Obviously, new processes in the world, such as globalization, imply a question about global responsibility, the source of which is the fact that societies are losing their local status. All humankind's course of life receives a single direction in the conditions of globalized world.

The idea of responsibility for technological progress has become one of the most important among modern ethical issues. During the twentieth century, philosophers such as Martin Heidegger, Friedrich Jünger, Jose Ortega y Gasset and Oswald Spengler discovered that technology can enslave us, deprive us of our original existence, and alienate us from our essence. We are bound to admit that technology is not only a source of new ethical problems, but it, in fact, changes what has heretofore been considered the moral constant of human existence. The introduction of science and technology into biological processes (as is the case with genetic engineering) creates a perfectly new type of intervention in the world of nature. The problem of responsibility is indicative of the crisis which we experience now, which results from the gap between activities and knowledge about the consequences of these activities. For a long

\footnotetext{
a Corresponding author: nplatonova79@inbox.ru
} 
time, the phenomenon of technology was not within the field of interest of philosophy. Technology was perceived as a morally neutral phenomenon. However, this changed after the invention of the nuclear bomb and nuclear weapons, as well as technogenic catastrophes in Chernobyl, Bhopal, and, finally, the 1970s fuel and energy crises in the West. The technological phobia (according to which technology is the main reason of human alienation from nature) has existed throughout the history of technology. From the very beginning, people had an ambivalent attitude towards technology. The Icarus myth tells us that, on the one hand, technology can liberate humans from gravity, but, on the other hand, it can bring about their destruction. In the Middle Ages inventors were accused of dealing with the devil. In the Modern Age, the technological phobia was expressed in the prohibition and destruction of technological inventions, which could undermine the habitual way of life of the society.

In the twentieth century, technological phobia became the main idea in existential philosophy since technologies restrained and depersonalized individuality as well as transformed all the world into a functional element of manufacture. Nevertheless, the negative side of technology is not the main question in this paper. The case can be made that technological civilization has shown the greatness of the human mind, invention, and will. Technology is a part of our fate which has its brighter and darker sides. Moreover, new problems, we are facing now in connection with technological development, have not been generated by the laws of technological evolution itself, but instead result from the rise of a new mentality. Therefore, the question of morals seems to be decisive: how might we use our moral abilities to prevent the negative consequences of technological activity? If the technological evolution leads to the conflict of values and humans have to realize the inevitability of choice, it means that the choice implies responsibility.

\section{Materials and methods}

In our study of responsibility we must first understand what we mean by responsibility and the special nature of responsibility in relation to technological activity. Responsibility is of course not a new concept in the history of ethics. We intend to advance an approach according to which responsibility is a relational concept, which acquires meaning only in connection with other ethical categories such as free will or fault. This is the Aristotelian concept of responsibility as a virtue, which primarily means self-respect and pride. Aristotle did not use the word "responsibility," but he indicated certain key aspects of the idea; his ethics still remains one of the most important sources of reflection on technological responsibility.

Another milestone in the history of thinking on responsibility is the philosophy of Immanuel Kant, in which the idea of responsibility is based on the premise of dignity of a human person as an autonomous being. Kant was the first philosopher who systematically used the words "responsibility" and "responsible" in ethical considerations. As the main locus of responsibility he pictured mind as foundation of the absolute moral law. The consequences of actions do not have any relevance to responsibility in Kant's absolutist ethics. A person is only responsible for motives of actions accomplished by him or her.

Methods of the research are different, firs of all; historical and philosophical reconstruction the idea of moral responsibility needs in order to present this idea as in whole. This method is used also to relate the notion of collective moral responsibility, so it lets us to fix different aspects between individual and collective responsibilities. Historical and philosophical reconstruction lets us check some assumptions to relate the idea of collective moral responsibility which this idea has. In this case, we use the logic reconstructions of philosophical approaches and hermeneutic way.

Using in this research social and philosophical analyses deal with recognizing those meaning's transformations which moral responsibility has today. Ethical notions have some peculiarities of function in social life, so it seems to correlate theoretical constrictions with real practice in order to understand how the moral consciences

An ethical analysis needs in order to describe mechanisms of moral estimations in collective actions.

\section{Results and discussion}

When we use the word "responsibility," we must bear in mind that the term is multivalued, integrated and polysemous. Multivaluedness means that the word "responsibility" is used in many different scientific and humanitarian disciplines, which define the content of responsibility in their boundaries. An integrated character of responsibility means that the concept refers to a relation engaging three heteronomous realms of Subject, Object and Instance. The polysemous feature of responsibility lies in the dilemmas raised by accurate assessment of the measure of individual and collective responsibility.

Responsibility means the ability of a person to act consciously and take into account the consequences of his or her actions. A person acting responsibly is capable of understanding the needs of other people. In addition, the sense of responsibility gives a person a sense of empowerment, a sense of possibility to influence the state of affairs and control certain events in the external world. Therefore, the expression "to bear responsibility" means to be able to take into account the consequences of accomplished actions. For a philosopher such a definition is acceptable, since responsibility is an essential attitude of a personality to a society, to another person and to herself or himself. As a result, we can say that responsibility has an intentional character. Of course, the idea of responsibility is closely linked to the idea of freedom, the latter being the condition of responsibility, in particular as autonomy. It is impossible to imagine a responsible action without freedom, 
understood not as absence of compulsion, but as an ability to act independently.

Freedom is the one of the fundamental ethical issues, which implies the idea of moral choice and definition of its conditions. The measure of a human's freedom correlates with the measure of her or his responsibility. In existential philosophy this responsibility spreads to all humanity. In contemporary philosophy the way in which the relation between freedom and responsibility is viewed has greatly changed. First of all, responsibility is no longer conceived as a form of necessity realized, but as an awareness of necessity in itself. Therefore, responsibility can be understood as a moral principle behind a given norm of behaviour. Such change in the status of responsibility was born from the progress of technological civilization, reflected in particular by the new ethics of responsibility advanced by Hans Jonas. This idea of responsibility takes into account the quantitative and qualitative changes in the nature of human activities, which now have acquired a global character. Jonas has come to the conclusion that traditional ethical ideas cannot solve problems created by the modern technology. In his opinion the heretofore ethic has lost its significance in the global world due to rapid changes of the pace of production oriented towards the needs of mass consumption. In previous ethics, responsibility was based on the ideas of a stable world and rational experience, so common sense and good will were enough to pass from words to deeds. It was one of the conditions of responsibility, and that condition was not a problem for ethics since responsibility was embedded directly in social relations [1].

The new ethics of responsibility accounts for the effect of the global scale of human life and the prospect of a distant future, as well as the problem of human survival. Nevertheless, we do not know how the idea of responsibility, which has a function of differentiation and pluralism, can help us to integrate the modern society. Thus we have questions to wonder about, such as who could assume the responsibility for the negative consequences of technological activity? Who could be the subject of such responsibility? Apparently, all the responsibility for the consequences is borne by engineers and scientists. In general, we are talking about a subject being a person who creates technologies. Nonetheless, it is erroneous to hold them responsible for all the negative consequences especially for political or economic decisions and results of these decisions.

First of all, it must be admitted that in the modern world many subjects exist whose activity is of a complex and collective nature, so individual responsibility apparently could disappear. Nevertheless, that situation calls for attention: on the one hand, an individual becomes subordinate to global structures, but, on the other hand, the significance of individual activity gains extreme importance. Nowadays a mistake of individuals can lead to a global catastrophe. Philosophers have tried to solve this problem using the concept collective subject of responsibility, which could be held responsible for all the negative consequences of technologic activity.

As far as scientific research is concerned, that problem was solved by the idea of distribution of responsibility among the members of a collective or a system. Nevertheless, since there are many new types of subjects in the modern world, the problem of collective responsibility is not limited to the problem of the distribution of duties between the individual and collective subjects. Therefore, the problem of responsibility is not restricted to only one system or one collective. We can have a situation when actions of many people or many groups may perfectly match the norm, but their accumulation can be the cause of calculative and synergetic effects with negative consequences. These subjects can act independently or compete with each other. For example, the disappearance of forests in Europe is a result of the pollution of the environment, to which many subjects contributed, and nobody can be held solely and exclusively responsible for such consequences.

In generally, the main assumption of collective moral responsibility is that all individuals in a collective are to be held responsible for other people's actions by tolerating, ignoring, or harboring them, even without actively collaborating in these actions.

The negative real or ideal sanctioning or judging can be ascribed to a person directly or indirectly, who has not been involved in an action, but, as the result, this action has moral reprehensible consequences. Using moral sanctioning in this case is based on people's belongs to social community, which can produce negative moral outcome.

According to this definition of collective moral responsibility researchers consider it is as a dishonest system of moral obligations. In other words, collective shares responsibility within collective independently from participation of its members. By the way, it is thought that the idea of collective responsibility is the way to escape moral responsibility, especially today when an autonomous acted agent can disappear in the complicated and organized practices. It can seem that collective character of activity reduces sense of responsibility because a person is not in charge of outcomes alone.

The idea of collective moral responsibility operates has a particular responsibility agent, which has not ever been focused on ethical theory. The sources of moral responsibility are groups or collectives, such as corporations, scientific technological groups, states, political and social institutes etc. As the agents of activity they can be source prosperity and the source of harm. The controversies of collective moral responsibility:

\section{The point of personality}

The notion of collective moral agent contradicts the idea of moral duty, which is always individual. Simultaneously, the concept of collective responsibility is contrary to the idea of social ethics of liberalism whose fundamental claim is that differences between individuals should be respected.

\section{The methodological point}

Another controversy of collective responsibility which some thinkers emphasize has been based on the idea of methodological individualism. This idea supposes that all social processes can be explained by 
reference to a set of principles governing individual human behavior. As the result, we are left with a situation in which in every researched case of collective activity we can reduce responsibility and find a guilty agent. Of course, such reduction of responsibility lets some people avoid it and other are forced to assume all responsibility.

Basically, in the past the problem of ascriptions was not complicated for certain. First of all, consequences of actions were predictable and it was not necessary to have complex scheme of ascriptions. Simplicity of ascription was supported by close interactions among people. By the way, unpredictable and long terms effects of human actions did not exist. In addition, moral imperatives were formulated as the fundamental principles although they had particular character.

Moral assessment was given after action, so it allows talking about backward-looking character of individual responsibility. Consciousness, shame and blameworthiness were the mechanism for individual responsibility. According to this mentioned definitions of responsibility we suppose that the classical ethical theory did not need a collective moral agent at all because a responsibility agent could be defined in any case.

Having described the paradigm of individual responsibility we would like to get certain answers following questions. First of all, does really collective responsibility reduce individual responsibility? Secondly, is it possible to keep individual bases of morality within collective activity?

Actually, many reflections of collective responsibility can be presented in three projects, where researchers attempts to justify possibility of moral assessment for actions of collective agents and try to proof moral status of collective agents. If we acknowledge existence of the collective responsibility, we should acknowledge that the collective responsibility requires collective intention The first feature of collective responsibility is cumulative responsibility of an aggregate of individuals as a whole [2].

Corporate Agent of Responsibility

The first project can be described as a Corporate Agent of Responsibility. Here personality is place into institutional and corporate context. Peter French rejected the anthropological prejudice of personality [3]. As the result, he has proposed a new concept of a person. A person is an agent, who possesses certain characteristics such as ability to act intentionally and to bring about changes in his or her environment. Secondly, this kind of agent can correct its behavior based on the past experience both positive and negative. Thirdly, a person is able to take interests of other subjects into account. French argues that some collectives could satisfy the conditions which we use for persons in the moral sense.

Some corporations are quite formed moral agencies endowed with rights and obligations. As I have already mentioned, responsibility is intrinsically linked to the intention. If we consider that a feature such as intention can be attributed to certain groups (in which case we would qualify it as a collective intention), we can treat them as agents of moral responsibility.
The collective intention realizes in «corporate internal decision-making structure (CID). This structure (CID) has two elements: firstly, an organizational or responsibility flow chart that delineates stations and levels within the corporate power structure [1]. Secondly, corporate decision recognition rule(s) usually embedded in something called corporation policy.

Thus, we deal with corporate decisions but not with decisions of individuals [2]. Corporations are collectives (or conglomerates) and their internal identity does not have strict connection with constant personal membership. P. French identifies moral individual position with moral position of collectives. Actually it is not correct we cannot to equalize their positions. Corporations are not moral personality and using the depersonalized structure in collectives does not guarantee that we would deal with real moral agent. In collective decisions we must accumulate will of all participants. It means that particular structure in collectives has to posses the democratic features, in other words, the atmosphere of publicity, taking into account different points and broad public discussions different projects. In this case, we have a chance to keep individual base of morality. Otherwise, the lack of democratic structure in collectives does not solve the problem of moral responsibility. That is why the French's model of corporate responsibility was supplemented with principals of publicity by A. Corlett [4]. In this context the mechanism of bearing responsibility can be realized through a shame. Using the notion of blameworthiness for corporations is not efficient because usually corporations have more pragmatic goal that moral, so the shame can be effective. Public censure is the strongest mechanism of effect for corporate than blameworthiness, because blameworthiness characters individual behavior, bur for corporate is more important confidents of partners.

Finally, organized collectives cannot be presented as a moral personality, but they are particular agents or «quasi personality», which can be accessed through moral norms.

\section{Vicarious Agent of Responsibility}

Another variant of collective agent is presented in Vicarious Notion of Responsibility. The vicarious responsibility can be described through moral notions such as blame, fairness and repentance of big groups such as nations, states, social institutes and professional organizations. On the whole, this type of collective responsibility means individual responsibility for activity and the consequences, which have been acted by others. The base of such responsibility is group affiliations. A group is an organizations or community which can be based on personal communication or can be unorganized group of aggregate people, who do not know each other, but they get involved in within different institutions. Also, those people can share common beliefs. In this project, the collective responsibility does not eliminate individual dimension of responsibility. Actually, sharing values with other people creates conditions for bearing responsibility. Physical participation in different actions does not play role because the most important 
mechanism of responsibility is symbolic meaning of our preferences shared with others [5]. These preferences can turn into steady practice, which can lead to consequences. The base of taking responsibility is an emotional experience of feeling guilty. Vicarious responsibility has a good potential. First of all, the complicated social dynamic and the crises of identity which are rooted in diffusion the notions of nation and state. Before this notions had provided for individuals particular social role and guaranteed part of irresponsibility in collective actions. Today decisions of collective agents are a subject of personal responsibility and care, because a person through the own preferences, values takes part in different organizations, social groups.

\section{Solidary Agent of Responsibility}

The last type of collective responsibility is Solidary or meta-institutional, where the main agent of responsibility is a human being. We can have a situation when actions of many people or many groups may perfectly match the norm, but their accumulation can be the cause of calculative and synergetic effects with negative consequences. These subjects can act independently or compete with each other. For example, the disappearance of forests in Europe is a result of the pollution of the environment, to which many subjects contributed, and nobody can be held solely and exclusively responsible for such consequences. In this case, individual responsibility minimizes or even disappears, so we have to say about global responsibility. However, humankind as the agent of responsibility is rather amorphous formation, which includes organized and unorganized groups. This type of responsibility begins when somebody takes moral obligation for a situation, an issue, but solution of this problem requests shared participation of other collective agents such as social institutes and different groups. Solidary responsibility has universal character and it has priority significant over other types of responsibility such as role, institutional or corporate responsibilities [6].

\section{Conclusion}

The issue of responsible agents is rather complicated today and the reason of this situation is rooted in the individual paradigm of responsibility. It seems such way cannot describe cases where we have dealt with collective and collaborating actions, so the necessity to extend ethical reflection is obvious.

The practice of Technology Assessment, which is presented as an independent collective agent of responsibility, can be taken as the variant how to control the technological process. This social institute let us get comprehensive estimations of new technologies and give hermeneutical analyses of our expectations from new technologies. The idea of collective responsibility has a heuristic significance for changed human activity today and it makes ethical theory prove unjustified escaping from moral responsibility.

Negative status of collective responsibility is getting over today through another interpretation of person.
Methodological individualism is a one of principles restricts in the complicated and mediated human activity today. Moreover reduction of responsibility lets some people avoid it and other are forced to assume all responsibility.

Individual responsibility does not correspond to new character of human activity, so this type of responsibility should be supplemented collective types of responsibility. Individual responsibility does not eliminate in the different types of collective responsibility, moreover all variants suggest the way to keep individual dimension of responsibility.

\section{Acknowledgment}

The programme was realized and subsided within the framework of the Programme for enhancing Tomsk Polytechnic University's competitiveness. The results presented herein were obtained with the assistance from Russian Fond.

\section{References}

1. H. Jonas, The Imperative of Responsibility: In Search of Ethics for the Technological Age (1984)

2. A. V. Prokof'iev, Voprosy filosofii (2004)

3. P. French, APQ, 16, (1979)

4. A. Corlett, RaP, (2006)

5. G. Mellema, APQ, (1984)

6. A. Platonova, M. Kokarevich, Procedia, 17, (2015) 